\title{
The development and implementation of a 12-month simulation-based learning curriculum for pediatric emergency medicine fellows utilizing debriefing with good judgment and rapid cycle deliberate practice
}

\author{
Justin M. Jeffers ${ }^{1 *}$ id and Shannon Poling ${ }^{2}$
}

\begin{abstract}
Background: There are currently training gaps, primarily procedural and teamwork skills, for pediatric emergency medicine (PEM) fellows. Simulation-based learning (SBL) has been suggested as an educational modality to help fill those gaps. However, there is little evidence suggesting how to do so. The objective of this project is to develop and implement an SBL curriculum for PEM fellows with established curriculum development processes and instructional design strategies to improve PEM fellowship training.

Methods: We developed a 12-month longitudinal SBL curriculum focused on needs assessment, instructional strategies, and evaluation. The curriculum development process led us to combine the instructional strategies of debriefing with good judgment, rapid cycle deliberate practice, and task-training to improve core PEM skills such as procedural competence, crisis resource management, and managing complex medical and traumatic emergencies. Using multiple approaches, we measured outcomes related to learners (attendance, performance, critical procedure opportunities), instructor performance, and program structure.

Results: Eight/Eight (100\%) PEM fellows participated in this curriculum from July 2015 to June 2017 with an overall attendance rate of $68 \%$. Learners self-reported high satisfaction $(4.4 / 5, \mathrm{SD}=0.5)$ and perceived educational value $(4.9 / 5, \mathrm{SD}=0.38)$ with the curriculum and overall program structure. Learners had numerous opportunities to practice critical procedures such as airway management (20 opportunities), defibrillator use (ten opportunities), and others (ten opportunities). Learner Debriefing Assessment for Simulation in Healthcare (short version) scores had mean scores greater than 5.8/7 (SD =0.89) across all six elements.

(Continued on next page)
\end{abstract}

\footnotetext{
* Correspondence: jjeffers@jhmi.edu

This project was previously presented as a platform presentation at the International Meeting for Simulation in Healthcare, San Diego, California, in January 2016, and at the International Pediatric Simulation Symposia and Workshops, Glasgow Scotland, May 2016.

'Department of Pediatrics, Bloomberg Children's Center, Division of Pediatric Emergency Medicine, Johns Hopkins University School of Medicine, Suite G-1509, 1800 Orleans St, Baltimore, MD 21287, USA

Full list of author information is available at the end of the article
}

(c) The Author(s). 2019 Open Access This article is distributed under the terms of the Creative Commons Attribution 4.0 International License (http://creativecommons.org/licenses/by/4.0/), which permits unrestricted use, distribution, and reproduction in any medium, provided you give appropriate credit to the original author(s) and the source, provide a link to the Creative Commons license, and indicate if changes were made. The Creative Commons Public Domain Dedication waiver (http://creativecommons.org/publicdomain/zero/1.0/) applies to the data made available in this article, unless otherwise stated. 
(Continued from previous page)

Conclusions: This longitudinal SBL curriculum combining debriefing with good judgment and rapid cycle deliberate practice can be a feasible method of reducing current training gaps (specifically with critical procedure opportunities) in PEM fellowship training. More work is needed to quantify the training gap reduction and to refine the curriculum.

Keywords: Curriculum development, Medical simulation, Pediatric emergency medicine training, Medical education, Rapid cycle deliberate practice, Debriefing with good judgment, Instructional design

\section{Background}

Clinical exposure is insufficient for pediatric emergency medicine (PEM) fellows to obtain key procedural and teamwork skills [1-9]. A review in 2013 found that out of 261 critical procedures performed during 194 patient resuscitations, pediatric emergency medicine fellows performed a median of three in a 12-month period [1] . Yet these critical procedures and team-based skills are important and required by the Accreditation Council for Graduate Medical Education (ACGME) [10]. Additionally, this lack of critical procedure exposure has a potential impact on faculty skill retention and therefore, potential patient care $[2,5]$.

The American Board of Pediatrics (ABP) and the Accreditation Council for Graduate Medical Education (ACGME) through their developmental milestone and entrustable professional activities (EPA) documents have suggested simulation-based learning (SBL) as a modality to help fill the training gap PEM fellows currently experience [11]. This is supported by the growing collection of evidence supporting SBL as an educational modality to improve the care we provide to the sickest patient populations [12-23].

The published literature identifies numerous individual scenarios and one-day curriculums for this learner group but there are no well-developed and well-described longitudinal SBL curriculums for pediatric emergency medicine fellows [24-29]. Prior to this curriculum, PEM fellows at this institution (tertiary care children's center) did not participate in any formal SBL training.

Currently, there is little evidence guiding choice of instructional strategies (IS) within SBL [30]. A goal during development of this 12-month longitudinal curriculum was to thoughtfully choose IS based on needs assessments, learner objectives, and instructional design principles.

Our overall aim was to develop an SBL curriculum based on instructional design principles to fill training gaps in PEM fellowship. In this article, we describe the design, implementation, and evaluation of this formative assessment curriculum.

\section{Methods}

\section{Overall curriculum development strategy}

The PEM fellowship at this institution is three years and has two fellows per year for a total of six learners per academic year. We used Thomas et al's 6-step approach to curriculum development [31] in conjunction with instructional design principles, including the Analysis, Design, Development, Implementation, and Evaluation (ADDIE) approach [32] to design this curriculum.

Instructional design is the systematic and reflective process of translating principles of learning into instruction [33]. There are numerous advantages to using systematic instructional design. Most relevant to this learner group include: 1. Encourages advocacy of the learner. 2. Supports effective, efficient, and appealing instruction. 3. Facilitates congruence among objectives, activities, and assessment [33] .

Similar to the way Thomas, et al. provide a systematic approach to curriculum development, the ADDIE approach provides a framework for a systematic approach to the analysis of learning needs, the design and development of a curriculum, and evaluation [34]. The ADDIE approach has been used to improve patient safety, procedural competency, as well as effectively changing clinical practice behaviors [35-37].

Based on these instructional design principles and in an effort to be efficient with the design and delivery of instruction, the curriculum development process for this project condensed the six steps into three: 1 . Needs assessment (combining problem identification, needs assessments, and goals and objectives) 2. IS and 3 . Evaluation (combining implementation and evaluation).

We implemented our curriculum from July 2015 through June 2017.

\section{Needs assessment}

We conducted four needs assessments to identify core areas in need of improvement and to guide development of our curriculum: [1] A literature search to determine training gaps. [2] A review of ACGME and AAP milestones and EPA's specific to PEM to ensure fellowship training compliance. [3] An anonymous on-line needs assessment survey of learners prior to participation in the curriculum. [4] A review of the past three years of PEM fellow in-service exam scores to identify low performing areas.

The search phrases, "pediatric emergency medicine training", "pediatric emergency medicine competencies", "pediatric emergency medicine education", "pediatric 
emergency medicine critical procedures", "pediatric skill acquisition", "pediatric skill retention", "pediatric crisis resource management education" were used to search literature identifying training gaps. The anonymous on-line survey addressed specific learner needs relating to perceived gaps in training and clinical experience.

The needs assessments were synthesized and reviewed to determine core deficits to be addressed. The needs assessments were also combined with the ACGME competencies to develop curricular goals.

\section{Instructional strategies}

Based on the results of the needs assessments, a systematic approach utilizing the ADDIE process was applied to determine the IS to be used [32].

\section{Evaluation}

Attendance was tracked, and all sessions were recorded to promote accurate assessment. The curriculum was evaluated formatively via end of session electronic surveys regarding session objectives, and summatively by an end of curriculum focus group of the six participants lead by the authors and end of curriculum anonymous on-line survey. Multiple assessment tools were used to evaluate and provide feedback to the learners for procedural skills and crisis resource management (CRM) [12, 38-40]. Critical procedure opportunities were tracked via video review. Instructor feedback and assessment was done via the Debriefing Assessment for Simulation in Healthcare Student Version` $\odot$ tool (DASH-SV) [41]. Descriptive analysis was used.

This study was reviewed and approved by our Institutional Review Board. All participants gave written informed to participate in this study. The datasets used and/or analyzed during the current study are available from the corresponding author on reasonable request.

\section{Results \\ ADDIE process \\ Analysis/needs assessments}

The literature search identified critical procedures and critical care management items $[1,2,4,5]$, which matched with PEM specific EPA's. All eight participants completed the learner needs assessment survey prior to participating in the curriculum. Several recurring needs such as procedural, CRM skills, and medical/trauma management of core PEM processes were discovered (Sample shown in Fig. 1). Open-ended survey questions, in-service exam scores of the eight participants and the informal discussions did not add additional needs. The analysis process focused the curriculum into two general categories: [1] Procedural/task skills and [2] CRM/teamwork skills, with the goal of integrating both categories as often as possible.

Table 1 illustrates the competency-based curricular goals in detail. Using the Pediatric Milestone Project and the needs assessments, a curricular goal was written for each of the seven competencies: patient care, medical knowledge, practice-based learning and improvement, interpersonal and communication skills, professionalism, systems-based practice, and personal and professional development. Each goal was linked with an evaluation strategy.

\section{Design}

Once the needs assessments and goals were completed and synthesized, the study team met to determine IS for the curriculum. After reviewing the literature, we

Learner Confidence With or Managing:

Crisis Resource Management Skills

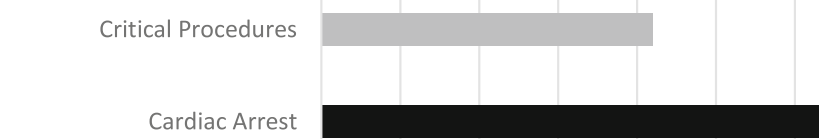

Toxicological Emergencies

Environmental Emergencies

Difficult Airways

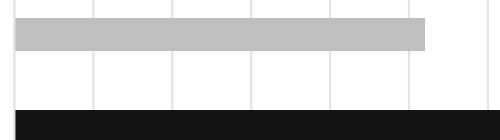

Fig. 1 Learner needs assessment: 5-point Likert scale

$\begin{array}{lllllllllll}0 & 0.5 & 1 & 1.5 & 2 & 2.5 & 3 & 3.5 & 4 & 4.5 & 5\end{array}$


Table 1 Global Competency-Based Curriculum Goals with Assessment Strategy

\begin{tabular}{|c|c|}
\hline Competency Based Goal (from Pediatric Milestone Project) & By the end of this curriculum, the learner will be able to: \\
\hline Patient Care & $\begin{array}{l}\text { Be proficient at diagnosis and treating a variety of pediatric emergency } \\
\text { medicine illnesses and processes using simulation-based learning and } \\
\text { apply it to real patients as measured via checklist and direct observation. }\end{array}$ \\
\hline Medical Knowledge & $\begin{array}{l}\text { Competently recognize and manage pediatric emergencies as well as } \\
\text { demonstrate pediatric emergency skills such as high-quality CPR, } \\
\text { defibrillation, and other minor procedures as measured via checklist. }\end{array}$ \\
\hline Practice-based Learning and Improvement & $\begin{array}{l}\text { Critically reflect on their own abilities and generalize to other areas of } \\
\text { patient care as measured via structured debriefing and faculty discussions. }\end{array}$ \\
\hline Interpersonal and communication skills & $\begin{array}{l}\text { Utilize appropriate crisis resource management and communication } \\
\text { strategies to improve teamwork as measured via checklist. }\end{array}$ \\
\hline Professionalism & $\begin{array}{l}\text { Demonstrate patient related professionalism such as empathy as well as } \\
\text { career professionalism such as timeliness and interprofessional respect as } \\
\text { measured via attendance tracking. }\end{array}$ \\
\hline Systems-Based Practice & $\begin{array}{l}\text { Integrate into an interprofessional setting and be competent leading a } \\
\text { crisis situation regardless of resources as measured via checklist. }\end{array}$ \\
\hline Personal and Professional Development & $\begin{array}{l}\text { Perform self-directed learning to continue to improve the skills required } \\
\text { to be a PEM physician as measured via tracking of articles distributed by learners. }\end{array}$ \\
\hline
\end{tabular}

determined that rapid cycle deliberate practice (RCDP) $[12,14]$ and debriefing with good judgment $[42,43]$ would best serve our curricular needs and goals.

Rapid Cycle Deliberate Practice is an emerging instructional strategy within SBL that has been shown to be beneficial for high stakes events and procedures such as high quality cardiopulmonary resuscitation, defibrillation, airway management, and team skills [12, 14, 27, 44]. Rapid cycle deliberate practice utilizes a facilitator-guided within-event debriefing approach [45] that maximizes the time learners spend in deliberate practice giving multiple opportunities to practice skills the correct way [14].

Debriefing with good judgement is a well-established debriefing method that uses debriefer observations of performance gaps to explore learner frames and thought processes [42, 43]. It uses a 3-phase (reaction, analysis, and summary) conversational approach based in reflective practice $[43,45]$. It can be used to improve a variety of skills such as teamwork and medical management principles.

There are numerous other reflective practice debriefing methods that have been shown to be effective [4649]. There is currently no definitive literature describing which method is better or best for a given situation or learner objective. The authors chose debriefing with good judgment based on its established track record, its associated assessment tool [50] and author familiarity and comfort. All sessions would be held in the institution's Medical Simulation Center.

\section{Development}

The development phase allowed the curriculum calendar to be finalized. A 12-month duration for the curriculum was chosen based on an estimated $66 \%$ attendance rate, allowing learners to be exposed to the curriculum twice during their three-year fellowship. This anticipated attendance rate is due to schedule challenges such as off campus rotations, on campus rotations that do not allow learners to participate, work hour rules, as well as past fellowship training conference attendance.

The sessions occurred monthly for 2-4h (Nine 2-h sessions and three 4-h sessions integrating specific procedural skills) (Table 2). Seasonality was considered as well as the importance of certain core skills. For example, hypothermia from cold water drowning was scheduled for winter and the first cardiac session focusing on pediatric advanced life support and CRM skills occurred early in the academic year.

Every month had a general core concept or need to be addressed such as cardiac or toxicology emergencies. Each two-hour session had two scenarios. One utilized debriefing with good judgment to focus on mental models, teamwork, and thought processing to fill in performance gaps. To promote retention and generalization, the second scenario was often related to the first. It utilized RCDP to focus on procedural skills, muscle memory, and integration of multiple ongoing processes such as advanced airway management concurrent with high quality cardiopulmonary resuscitation. The four-hour sessions included procedural skills such as ultrasound and advanced airway management. These skills were integrated into scheduled scenarios for that session. A typical 4-h procedural session consisted of a 2-h skills workshop followed by two scenarios to provide clinical context and reinforce the recently acquired skills. Procedural, teamwork, and CRM skills were reinforced numerous times throughout the curriculum to promote 
Table 2 Curricular Content Calendar

\begin{tabular}{ll}
\hline $\begin{array}{l}\text { Month (Hours) } \\
\text { Bold Identifies } \\
\text { Procedural Skills Days }\end{array}$ & Content (Core - Specific cases) \\
\hline July [2] & Cardiac 1 - PEA, VF \\
August [4] & Trauma - Abdomen, Head \\
& Skills - Chest Tube, Pericardiocentesis \\
September [2] & Shock 1 - Septic, Neurogenic \\
October [4] & Respiratory 1 - Status Asthmaticus, \\
& Acute Chest \\
& Airway Skills Day - Laryngeal Mask Airway, \\
& Cricothyrotomy, Difficult Airway Management \\
November [2] & Toxicology - Tri-Cyclic Antidepressant, Iron \\
December [2] & Environmental - Drowning (hypothermia), \\
January [2] & Electrocution \\
& Cardiac 2 - Supraventricular Tachycardia, \\
February [2] & Pulseless Ventricular Tachycardia \\
& Respiratory 2 - Upper Airway Obstruction, \\
March [2] & Aspiration pneumonia \\
& Endocrine - Diabetic Ketoacidosis with Cerebral \\
April [2] & Edema, Thyroid Storm \\
May [2] & Renal - Hypertensive Emergency, Acute renal \\
failure leading to ventricular fibrillation
\end{tabular}

retention. For example, airway management procedures were needed during numerous months and not just during the airway skills session.

The purpose of focusing on monthly core concepts was to allow some flexibility in scenario usage. Specifically, flexibility in relating to recent real patients allowing for more reinforcement and generalization. For example, if the core concept was abdominal trauma and there was a recent real abdominal trauma event that presented a challenge, a scenario would be written to reflect that real-life situation as opposed to a generic scenario.

The primary author was the core educator and was present at all sessions. The second author, a medical simulation center medical educator and respiratory therapist, was present for most sessions and offered expertise with the development and content delivery of the curriculum. Other content experts were invited to participate when appropriate. For example, a PEM ultrasound expert participated during ultrasound heavy sessions.

\section{Implementation}

For three months prior to the July 2015 full implementation, core concepts were piloted. Minor adjustments were made to those scenarios related to time management. One four-hour skills day (access) was piloted during that time. No adjustments were required. This pilot period provided an outline for the development of scenarios and skills day structure throughout the curriculum. The pilot period also supported the estimated $66 \%$ attendance rate.

\section{Evaluation/feedback}

Evaluation strategies focused on five areas: [1] Attendance. [2] Learner satisfaction, perceived educational value, and potential curricular changes from end of curriculum survey and focus group session. [3] Specific scenario objectives from end of session survey. [4] Number of critical procedure opportunities per observation and video review. [5] Instructor performance per learner completed DASH-SV@ forms. A sixth area, quantitative performances on certain critical procedural skills via various checklists and assessment tools is not reported due to low $n$ but is ongoing.

Attendance for the year-long curriculum was $68 \%$ (65/96 possible participation opportunities). Given the low $n$ of eight, quantitative performance assessments have been collected but not analyzed. Overall, the learners found self-reported high satisfaction $(4.4 / 5, \mathrm{SD}=0.5)$ and educational value $(4.9 / 5, \mathrm{SD}=0.38)$ in the curriculum with an $88 \%$ response rate (7/8 participants) but did suggest areas of improvement and future direction (Table 3). The end of curriculum focus group further reinforced these future changes. End of session electronic surveys asking if objectives were met for each learning session had a score of $4.7 / 5(\mathrm{SD}=0.62)$ with $82 \%$ survey completion $(53 / 65)$.

Learners were exposed to numerous critical procedure opportunities (often multiple opportunities per session) during the 12-month curriculum. Each learner had up to 20 airway skills opportunities, ten defibrillator use opportunities, and ten opportunities for other procedures such as pericardiocentesis, central line insertion, and chest tube insertion. Mean total critical care procedures performed were $27(\mathrm{SD}=2.4), 67.5 \%$ of total opportunities.

Learner DASH-SV(c) evaluations were done quarterly for a total of 21 evaluations (consistent with attendance

Table 3 Future Directions

\begin{tabular}{ll}
\hline Change & Implementation \\
\hline Increase Ultrasound & $\begin{array}{l}\text { Review curriculum and discuss with } \\
\text { ultrasound expert regarding more ways to } \\
\text { integrate ultrasound training and practice }\end{array}$ \\
Increase Realism & $\begin{array}{l}\text { Move some months to an in-situ setting } \\
\text { and recruit pediatric emergency department } \\
\text { nurses, technicians, faculty, and other learners } \\
\text { such as emergency medicine and } \\
\text { pediatric residents } \\
\text { Create an adjunct curriculum focusing on } \\
\text { Include Medical } \\
\text { Education Component } \\
\text { related instructional strategies leading to } \\
\text { opportunities for the learners to participate } \\
\text { in a peer-to-peer SBL educational process }\end{array}$ \\
\hline
\end{tabular}


rates). Mean scores for all six elements were above 5.8 (maximum of seven). The lowest scoring element was element three (The instructor structured the debriefing in an organized way) with a mean score of $5.8(\mathrm{SD}=0.89)$. The maximum scoring elements were element two (Engaging context for learning) and element six (How to improve or sustain good performance) with a mean score of seven.

\section{Discussion}

This is a description of the development, implementation, and evaluation of a longitudinal SBL curriculum for PEM trainees. It utilized debriefing with good judgment and RCDP. Combining a more traditional curriculum development approach along with the instructional design ADDIE approach allowed us to thoughtfully and efficiently design a curriculum to meet the needs of the learners and address current training gaps in PEM training.

There is one other longitudinal SBL curriculum for PEM trainees in the literature [29]. There are a number of issues and differences worth noting. First, the curriculum described by Chen, et al. does not describe their development process with significant detail. Providing significant details about our instructional design and curriculum development process makes it more generalizable and easier to reproduce or adapt to other training program needs.

Second, PEM fellowship training programs in Canada are two years in length versus three years in the United States. The difference in training time can potentially make a difference when considering how to integrate SBL into PEM training programs.

Third, there is distinct difference in evaluation strategies between the two curriculums. Cheng et al. only used a 12-item satisfaction survey to evaluate their curriculum [29]. We implemented a robust evaluation strategy with numerous methods in an attempt to more completely evaluate learner and instructor performance as well as performance of the curriculum itself. By using a more robust evaluation strategy, we are well set-up to make changes to accommodate future learner needs.

Other published curriculums for this learner group are not as thorough as this curriculum. They tend to focus on either a single training gap such as trauma management [51] or delivering challenging news [52], focus on a single piece of the curriculum development process [53], or do not as thoroughly describe their process [51]. As a result, we believe our curriculum is the most generalizable and adaptable curriculum to date.

The $68 \%$ attendance is low but is as expected given the overall fellowship curricula setup. During curricular planning and development, a $66 \%$ attendance was anticipated. Given the $68 \%$ attendance rate, the 12-month curricular structure exposes the learners to the entire curriculum twice during their three years of fellowship training, potentially reinforcing and generalizing learning.

An important training gap identified during the needs assessment phase is a lack of clinical opportunities to perform critical procedures. It has been shown that PEM fellows perform a median of three critical procedures in a 12-month period [1]. This curriculum provided nine times that amount per year. Although learners only completed $67.5 \%$ of potential critical procedure opportunities, this does fall in-line with learner attendance (68\%) implying procedure opportunities are evenly and well-spaced throughout the curriculum. What remains unclear, is if this increase in SBL procedural experience translates to clinical success with this learner group.

Instructor quality was also rated highly via DASH-SV@ evaluations. The DASH-SV@ is a well-established debriefing assessment tool with sound validity evidence $[41,50]$. Utilizing this type of learner feedback is important in the context of the overall evaluation strategy for a few reasons. First, it provides direct learner feedback to the instructor in real-time. This allows instructors to adapt and alter their approaches as needed to better meet the needs of the learners. Second, it allows learners to potentially feel more involved with the curriculum development and adjustment process. Lastly, this type of evaluation allows for comparisons between instructors. This information can be used to maximize instructor quality longer term.

Overall, instructor performance was rated very highly. Element three of the DASH-SV@, structuring the debriefing in an organized way, scored the lowest of the seven elements. Effort will be put into improving element three.

There are several limitations to our study. First, the primary author was the assistant fellowship program director. This may have led to biased survey responses. This risk was minimized by the anonymous nature of the surveys. There is also potential bias from the end of curriculum in-person focus group as the primary author lead the focus group. Going forward, this risk will be minimized by having a person not connected to the curriculum or the fellowship lead the focus group. Second, the small number of study subjects makes assessment and generalization of results challenging. Related, is the lack of quantitative data regarding critical procedure performance. This was due to the current low $n$ and would not provide meaningful information. This data collection is ongoing and at this time, being used for individual learner feedback. These limitations will be minimized going forward as more learners participate and more data is collected. 


\section{Conclusion}

This curriculum received a positive response from learners. Formative and summative assessments found increased critical procedure opportunities and high instructor performance. Future changes include more ultrasound integration, in-situ simulations, and a peer-to-peer education component. Continual assessment and sound instructional design processes will further revise curriculum going forward.

\begin{abstract}
Abbreviations
ABP: American Board of Pediatrics; ACGME: Accreditation Council for Graduate Medical Education; ADDIE: Analysis, Design, Development, Implementation, and Evaluation; CRM: Crisis resource management; EPA: Entrustable professional activities; IS: Instructional strategy (ies); PEM: Pediatric Emergency Medicine; RDCP: Rapid cycle deliberate practice; SBL: Simulation-based learning
\end{abstract}

\section{Acknowledgements}

We would like to thank the Medical Simulation Center at Johns Hopkins University School of Medicine for their time, resources and support with this project.

\section{Funding}

No funding was received for this project.

\section{Availability of data and materials}

The datasets used and/or analyzed during the current study are available from the corresponding author on reasonable request.

\section{Authors' contributions}

JJ developed and implemented the curriculum, collected and analyzed data, and wrote the manuscript. SP developed and implemented the curriculum. All authors have read and approved the final version of this manuscript.

\section{Ethics approval and consent to participate}

This project was approved by the Johns Hopkins University IRB. Written informed consent was obtained.

\section{Consent for publication}

Not applicable.

\section{Competing interests}

The authors declare that they have no competing interests.

\section{Publisher's Note}

Springer Nature remains neutral with regard to jurisdictional claims in published maps and institutional affiliations.

\section{Author details}

'Department of Pediatrics, Bloomberg Children's Center, Division of Pediatric Emergency Medicine, Johns Hopkins University School of Medicine, Suite G-1509, 1800 Orleans St, Baltimore, MD 21287, USA. Johns Hopkins Medical Simulation Center, Johns Hopkins University, 600 North Wolfe Street, Blalock 701, Office 702A, Baltimore, MD 21287, USA.

\section{Received: 2 October 2018 Accepted: 3 December 2018}

\section{Published online: 15 January 2019}

\section{References}

1. Mittiga MR, Geis GL, Kerrey BT, Rinderknecht AS. The Spectrum and frequency of critical procedures performed in a pediatric emergency department: implications of a provider-level view. YMEM. Elsevier Inc. 2013; 61(3):263-70.

2. Green SM. How does one learn critical care procedures in a pediatric emergency department? YMEM Elsevier Inc. 2013;61(3):279-80.

3. Donoghue AJ, Ades AM, Nishisaki A, Deutsch ES. Videolaryngoscopy versus direct laryngoscopy in simulated pediatric intubation. YMEM. Elsevier Inc 2013;61(3):271-7.
4. Mittiga MR, FitzGerald MR, Kerrey BT. A Survey Assessment of Perceived Importance and Methods of Maintenance of Critical Procedural Skills in Pediatric Emergency Medicine. Pediatr Emerg Care. 2017; Publish Ahead of Print:1.

5. Green SM, Ruben J. Emergency department children are not as sick as adults: implications for critical care skills retention in an exclusively pediatric emergency medicine practice. JEM Elsevier Inc. 2009;37(4):359-68.

6. Schoenfeld PS, Baker MD. Management of cardiopulmonary and trauma resuscitation in the pediatric emergency department. Pediatrics. 1993;91(4):726-9.

7. Guilfoyle FJ, Milner R, Kissoon N. Resuscitation interventions in a tertiary level pediatric emergency department: implications for maintenance of skills. CJEM. 2015;13(02):90-5.

8. Claudet I, Bounes V, Federici S, Laporte E, Pajot C, Micheau P, et al. Epidemiology of admissions in a pediatric resuscitation room. Pediatr Emerg Care. 2009;25(5):312-6.

9. Chen EH, Cho CS, Shofer FS, Mills AM, Baren JM. Resident exposure to critical patients in a pediatric emergency department. Pediatr Emerg Care. 2007;23(11):774-8

10. 2016-07-01 ACFGME2-0-1, 2013. ACGME program requirements for graduate medical education in pediatric emergency medicine.

11. The Pediatrics Milestone Working Group. The Pediatric Milestone Project. Available at: https://www.abp.org/sites/abp/files/pdf/milestones.pdf. Accessed April 16, 2015

12. Jeffers J, Eppich W, Trainor J, Mobley B, Adler M. Development and evaluation of a learning intervention targeting first-year resident defibrillation skills. Pediatr Emerg Care. 2016;32(4):210-6.

13. Mangold KA, Jeffers JM, Burns RA, Trainor JL, Unti SM, Eppich W, et al. An objective structured clinical examination to improve formative assessment for senior pediatrics residents. Journal of Graduate Medical Education. 2015; 7(3):470-4.

14. Hunt EA, Duval-Arnould JM, Nelson-McMillan KL, Bradshaw JH, Diener-West M, Perretta JS, et al. ARTICLE IN PRESS. In: Resuscitation. European Resuscitation Council, American Heart Association, Inc., and International Liaison Committee on Resuscitation. Ireland Ltd: Published by Elsevier; 2014. p. 1-7.

15. Cheng A, Hunt EA, Donoghue A, Nelson-McMillan K, Nishisaki A, LeFlore J, et al. Examining pediatric resuscitation education using simulation and scripted debriefing. JAMA Pediatr. 2013;167(6):528-1.

16. Cheng A, Brown LL, Duff JP, Davidson J, Overly F, Tofil NM, et al. Improving cardiopulmonary resuscitation with a CPR feedback device and refresher simulations (CPR CARES study). JAMA Pediatr. 2015;169(2):137.

17. Kurosawa H, Ikeyama T, Achuff P, Perkel M, Watson C, Monachino A, et al. A randomized, controlled trial of in situ pediatric advanced life support recertification ("pediatric advanced life support reconstructed") compared with standard pediatric advanced life support recertification for ICU frontline providers*. Crit Care Med. 2014;42(3):610-8.

18. Hunt EA, Vera K, Diener-West M, Haggerty JA, Nelson KL, Shaffner DH, et al. Delays and errors in cardiopulmonary resuscitation and defibrillation by pediatric residents during simulated cardiopulmonary arrests. Resuscitation. 2009:80(7):819-25.

19. Hunt EA, Walker AR, Shaffner DH, Miller MR, Pronovost PJ. Simulation of inhospital pediatric medical emergencies and cardiopulmonary arrests: highlighting the importance of the first 5 minutes. Pediatrics. 2008;121(1):e34-43.

20. Hunt EA, Fiedor-Hamilton M, Eppich WJ. Resuscitation education: narrowing the gap between evidence-based resuscitation guidelines and performance using best educational practices. Pediatr Clin N Am. 2008;55(4):1025-50.

21. Barsuk JH, Cohen ER, McGaghie WC, Wayne DB. Long-term retention of central venous catheter insertion skills after simulation-based mastery learning. Acad Med. 2010;85:S9-S12.

22. Barsuk JH, Ahya SN, Cohen ER, MCGaghie WC, Wayne DB. Mastery learning of temporary hemodialysis catheter insertion by nephrology fellows using simulation technology and deliberate practice. YAJKD. National Kidney Foundation, Inc. 2009;54(1):70-6.

23. Barsuk JH, Cohen ER, Caprio T, WC MG, Simuni T, Wayne DB. Simulationbased education with mastery learning improves residents' lumbar puncture skills. Neurology. 2012;79(2):132-7.

24. Burns R, Stone K, Reid J, Malik F, Cheng A. Pediatric Emergency Medicine Simulation Curriculum: Thyroid Storm: MEP; 2015. https://doi.org/10.15766/ mep_2374-8265.10062

25. Thomas A, Sanseau E, Uspal N, Burns R, Auerbach M, Caglar D, et al Pediatric emergency medicine simulation curriculum: submersion injury with hypothermia and ventricular fibrillation. MEP. 2017;13. 
26. Schuh A, Burns R, Reid J. Stone K. Hyperkalemia Due to Congenital Adrenal Hyperplasia. MEP: Pediatric Emergency Medicine Simulation; 2015.

27. Doughty C, Welch-Horan T, Hsu D, Fielder E, Pereira F. Little-Wienert K, et al. MEP: Rapid Cycle Deliberate Practice Pediatric Simulation Scenarios; 2015.

28. Adler MD, Vozenilek JA, Trainor JL, Eppich WJ, Wang EE, Beaumont $J$, et al. Development and evaluation of a simulation-based pediatric emergency medicine curriculum. Acad Med. 2009 Jul;84(7):935-41.

29. Cheng A, Goldman RD, Aish MA, Kissoon N. A simulation-based acute care curriculum for pediatric emergency medicine fellowship training programs. Pediatr Emerg Care. 2010 Jul;26(7):475-80.

30. Cook DA, Hamstra SJ, Brydges R, Zendejas B, Szostek JH, Wang AT, et al. Comparative effectiveness of instructional design features in simulationbased education: systematic review and meta-analysis. Med Teach. 2013 Jan;35(1):e867-98

31. Thomas PA, Kern DE, Hughes MT, Chen BY. Curriculum development for medical education: a six-step approach; 2015.

32. Morrison GR. Ross SM. Kalman H. Designing effective instruction: Kemp JE; 2010.

33. Smith PL, Ragan TJ. Instructional design; 2005

34. Patel SR, Margolies PJ, Covell NH, Lipscomb C, Dixon LB. Using instructional design, analyze, design, develop, implement, and evaluate, to develop elearning modules to disseminate supported employment for community behavioral health treatment programs in New York state. Front Public Health. 2018 May 7:6:4-9.

35. Tariq M. Optimum number of procedures required to achieve procedural skills competency in internal medicine residents. BMC Medical Education. BMC Medical Education; 2015 Oct 22;:1-9.

36. Battles JB. Improving patient safety by instructional systems design. Quality and Safety in Health Care. 2006 Dec 1;15(suppl_1):i25-9.

37. Malan Z, Mash B, Everett-Murphy K. Development of a training programme for primary care providers to counsel patients with risky lifestyle behaviours in South Africa. Afr j prim health care fam med. 2015 Feb 11;7(1):885-8.

38. Salamonsen MR, Bashirzadeh F, Ritchie AJ, Ward HE, Fielding DIK. A new instrument to assess physician skill at chest tube insertion: the TUBEiCOMPT. Thorax. 2014 Mar;26.

39. Hartman N, Wittler M, Askew K. Manthey D. American Journal of Medical Quality: Delphi Method Validation of a Procedural Performance Checklist for Insertion of an Ultrasound-Guided Internal Jugular Central Line; 2014 Sep 10.

40. Eppich W, Nannicelli AP, Seivert NP, Sohn M-W, Rozenfeld R, Woods DM et al. A rater training protocol to assess team performance. J Contin Educ Heal Prof. 2015 Jun 26;35(2):83-90.

41. Brett-Fleegler M, Rudolph J, Eppich W, Monuteaux M, Fleegler E, Simon R. Debriefing assessment for simulation in healthcare. Simulation in Healthcare: The Journal of the Society for Simulation in Healthcare. 2012 Oct; $7(5): 288-94$.

42. Rudolph JW, Simon R, Raemer DB, Eppich WJ. Debriefing as formative assessment: closing performance gaps in medical education. Acad Emerg Med. 2008 Nov;15(11):1010-6.

43. Rudolph JW, Simon R, Rivard P, Dufresne RL, Raemer DB. Debriefing with good judgment: combining rigorous feedback with genuine inquiry. Anesthesiol Clin. 2007 Jun;25(2):361-76.

44. Patricia K, Lemke D, Arnold J. Rapid cycle deliberate practice: application to neonatal resuscitation. MEP. 2017;13.

45. Sawyer T, Eppich W, Brett-Fleegler M, Grant V, Cheng A. More than one way to debrief. Simulation in Healthcare: The Journal of the Society for Simulation in Healthcare. 2016 Jun;11(3):209-17.

46. Eppich $W$, Cheng A. Promoting excellence and reflective learning in simulation (PEARLS). Simulation in Healthcare: The Journal of the Society for Simulation in Healthcare. 2015 Apr;10(2):106-15.

47. Zigmont JJ, Kappus $L$, Sudikoff SN. The 3D model of debriefing: defusing, discovering, and deepening. YSPER Elsevier Inc. 2011 Apr 1;35(2):52-8.

48. Kolbe M, Weiss M, Grote G, Knauth A, Dambach M, Spahn DR, et al. TeamGAINS: a tool for structured debriefings for simulation-based team trainings. BMJ Qual Saf. 10. 2013:22(7):541-53.

49. Jaye $P$, Thomas $L$, Reedy G. "The Diamond": A structure for simulation debrief. Clinical Teacher. Wiley/Blackwell; 2015;12(3):171-175.

50. Simon R, Raemer DB, Rudolph JW. Debriefing Assessment for Simulation in Healthcare (DASH)@ - Student Version, Short Form. Center for Medical Simulation, Boston, Massachusetts. 2010. https://harvardmedsim.org/wpcontent/uploads/2017/01/DASH.SV.Short.2010.Final.pdf. English, French, German, Japanese, Spanish.
51. McLaughlin CM. Impact of simulation-based training on perceived provider confidence in acute multidisciplinary pediatric trauma resuscitation. Pediatric Surgery International. Springer Berlin Heidelberg; 2018;34(12):1353-1362.

52. Chumpitazi CE, Rees CA, Chumpitazi BP, Hsu DC, Doughty CB, Lorin ML. Creation and Assessment of a Bad News Delivery Simulation Curriculum for Pediatric Emergency Medicine Fellows. Cureus. 2016;1:1-13.

53. Bank I, Cheng A, McLeod P, Bhanji F. Determining content for a simulationbased curriculum in pediatric emergency medicine: results from a national Delphi process. CJEM Cambridge University Press. 2015 Nov;17(6):662-9.

\section{Ready to submit your research? Choose BMC and benefit from:}

- fast, convenient online submission

- thorough peer review by experienced researchers in your field

- rapid publication on acceptance

- support for research data, including large and complex data types

- gold Open Access which fosters wider collaboration and increased citations

- maximum visibility for your research: over $100 \mathrm{M}$ website views per year

At $\mathrm{BMC}$, research is always in progress.

Learn more biomedcentral.com/submissions 